\title{
Scientific Thinking on the Teaching Management Information in Colleges and Universities
}

\author{
Chunfang Wang \\ School of Humanities, Jilin Agricultural University, Changchun 130118, China \\ (E-mail:wangchunfang1975@tom.com)
}

Keywords: Teaching management; information structure; training scheme

\begin{abstract}
With the vigorous development of China's higher education and the deepening of the reform of higher education, the teaching management is bound to enter the era of information. Through the analysis of the problems currently existing in the management of university information teaching, this paper puts forward the scheme of taking talent training as the core of information management, designs the structure system of teaching management information, and realizes the integration of process and the results, teaching management and information management and service. The theory and thinking of the teaching management information system based on regarding the training plan as the core has an important significance in carrying out the innovation of the teaching management information construction in Colleges and universities.
\end{abstract}

\section{Significance of Information Construction of Teaching Management in Colleges and Universities}

It meets the needs of social development for the construction of information technology in Colleges and Universities. With the continuous development of society, modern information technology is penetrating in various fields of production and life. In order to make the higher education to keep pace with the times to adapt to the social development, in March 2012, the Ministry of Education issued the "Education information ten-year development plan (2011 - 2020)", which better provided policy guidance and basis for the information construction of Colleges and universities.

It improves the efficiency and quality of teaching management. Teaching management work covers a wide range and the links are complex, involving all the teachers and students. In practical work, it not only has the management of daily affairs, but also provides services for teachers and students. Therefore, facing numerous service demand for the limited management personnel, the introduction of information can span the limit of time and space, timely synchronize various data resources and form sharing, which not only saves human resources, but also saves much time resources of various staffs and achieves another sense of overall arrangement, effectively improving the teaching management efficiency and quality and satisfaction of teachers and students [1].

It promotes the standardization and normalization of teaching management. Teaching management is a process of institutionalization and standardization. Teaching management information construction can realize that the teaching activities participants in the coordination of teaching management departments, make the work of teaching activities more standardized. The teaching management information achieves data storage unified and standard, data processing method unified, data query method unified, and data print format unified, realizes the standardization of teaching management, avoids the randomness of traditional teaching management, ensures the teaching work orderly, stably and efficiently, and effectively promotes the teaching management standardization and normalization.

\section{Present Situation and Existing Problems of Teaching Management Information Construction in Colleges and Universities}

College teaching management information is established o the basis of the teaching management mode, and its specific form is the construction of teaching management information system platform. However, there are a lot of problems in the construction of teaching management 
information system in Colleges and universities in our country at present.

\subsection{Lack of Core Concepts}

According to the basic principle of educational management, teaching management of any university must have a core, and only around a core can it straighten out every link of teaching management and form the organic system and develop a teaching management information system which adapts to the school teaching management mode in the process of information construction. However, at present a lot of teaching management in Colleges and universities lack the scientific core idea, the management process has no fixed starting point, and resource construction and decision support have no unified basis, resulting in that the teaching management information system developed by the software company lacks the top-level design of scientific concept support, and the system framework disjointing from the teaching management system architecture, not matching with the mode of teaching management and school requirements.

\subsection{Deficiency of Rational Planning}

Many Colleges and universities, in the process of teaching management information technology, lack unified planning, unified coordination and it cannot catty out overall planning from the school and even the macro level of the whole higher education system, and there is not enough research on the problems in the process of school teaching management and information technology. As a matter of fact, in terms of the development of teaching management information system, focus of the software development company is only on the implementation of software development and function, and the key to the development and application of the system is the school's systematic and basic work before the software is developed, including system organization and management system, the system user needs investigation and analysis, the total target function and the function of each module, and the core concept and the main structure the system developed and so on. These all need Colleges to combine with school personnel training system, teaching management concept and mode, rules and regulations and considerable training plan to carry out a considerable preparatory work.

\subsection{Absence of Spiritual Culture}

No matter Colleges autonomously develop or purchase commercial teaching management information system, at present, due to the lack of unified technical standards, the core development process and the main structure, it results in that the versatility of a lot of College system is not strong, the process and result of teaching management, management and service and so on are not effectively integrated. It neither makes scientific management of teaching resources nor carries out whole-process management of the teaching process and the teaching support service. In addition, it is not adaptable to or disconnect with the reform of the teaching mode implemented, or even the data that the software outputs violate the basic rules of education and teaching, lack of flexibility, humanization in implementation procedures, having restraint effect on the teaching management reform work.

\section{Research and System Architecture of Teaching Management Information}

According to "Education information ten-year development plan (2011 - 2020)" by the Ministry of Education, the objectives of teaching management information construction in Colleges and universities is mainly reflected in the following aspects [2]. The first one is to boost the innovation of teaching management concept. Through the construction of information, analyze the problems existing in the process of teaching management, innovate the core concept of teaching management, make the core concept of the teaching management system integrate with information system framework, realize the integration of teaching management process and results, management and service, management system and information system and so on, and boost the teaching management decision-maker and manager from the thought to continuously innovate teaching management service concept. The second is to promote the fine management of teaching management. Through the information construction, promote the perfect and innovation of teaching management system, so the teaching management process become procedure-orientation, standardization, refinement, and achieve the information system management of the whole process. The third is to strengthen the standardization of teaching behavior. Through the application of information system platform, make teacher's teaching behavior and students' learning behavior more standardized. 


\subsection{Foundation of Innovation of Teaching Management Mode - Take "Training Scheme" as the Core}

The training scheme is a programmatic document for the cultivation of talents in universities. The guarantee and improvement of the quality of talent cultivation is the key to ensure the training plan being scientific, advanced, authoritative and normative. Training scheme maintains the key position in the process of personnel training. After years of exploration and practice research, research group puts forward the concept of taking "training scheme" as the core of teaching management mode innovation, whose connotation is that the starting point of the process of teaching management is the training scheme. Training scheme runs through the whole process of teaching management, and the initial starting point is the training scheme; the standard of teaching management evaluation and teaching quality monitoring is the training scheme. The quality of teaching process and performance evaluation, personnel training quality evaluation, talents quality evaluation and so on of teachers' teaching management departments at all levels take the objective and requirement in training scheme as the standard; the basis for the analysis of teaching management decision-making is training scheme. The teaching task review and revision, teaching conditions and the construction of teachers' team, teaching funding allocation and a series of decisions take the training scheme as the basis, and the reforming breakthrough of talent training mode and means is the training scheme.

\subsection{Coupling Foundation of the Two Systems of Teaching Management and Information} System - Take "Training Scheme" as the Core

To take "training scheme" running through "the teaching management system" and "information system frame construction system", is a new mode of teaching management mode innovation and information system construction in Colleges and universities. First of all, take "training scheme" runs through the teaching management system. University teaching management includes several modules of enrollment plan management, training scheme management, course management, course arrangement management, course selection management, test management, performance management, student management, teaching evaluation management, graduation management, teaching resource management, decision support service management and so on, through constructing teaching management mode taking the core of training scheme (as shown in Figure 1) [3], the teaching management system has become an organic whole.

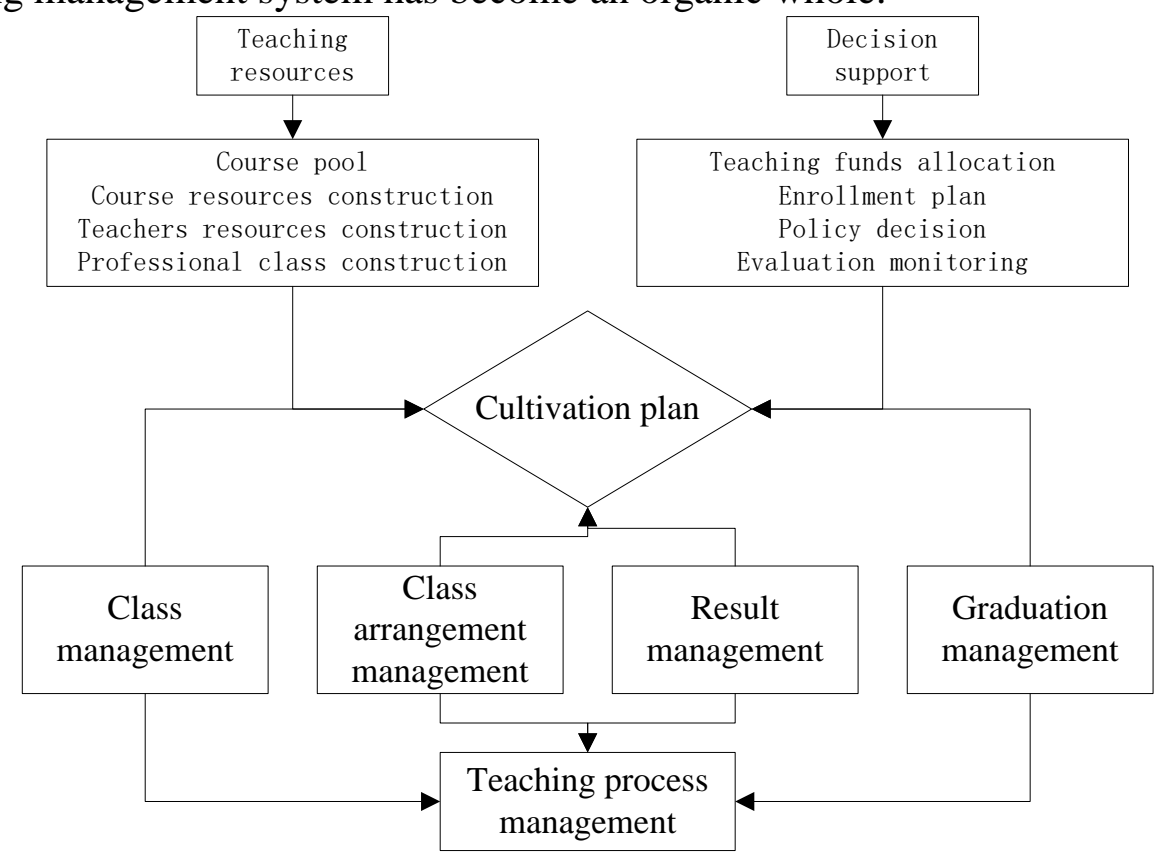

Figure 1 The teaching management mode taking the core of training scheme

The second is that to take "training scheme" running through the information system construction of teaching management information system is the information realization of school teaching management information, and the process of teaching management determines the process of information system architecture. The requirements of each link determines the functional module design that the information system corresponds to, and the requirements of the resource 
management and decision support determines the design of the data statistical functions of the information system.

\subsection{Guarantee for the Realization of Two Fusions - Take "Training Scheme" as the Core}

Put forward taking training scheme as the core running through the concept of framework of the teaching management information system, make organic coupling of the teaching management system and information system architecture, and achieve two fusions: one is through the teaching management, to manage the whole process of the teaching management and compare and analyze the operating result in each link of the management process, and realize the fusion of process and result [4]. The second is, in the process of teaching management structure, reconstruction of management system, and information management, to attach importance to the fusion of teaching management and service, to show standardized management and service diversity, so as to fully mobilize the teaching management and service enthusiasm and creativity, realizing the fusion of teaching management and service.

\section{Practical Design of Teaching Management Information Construction in Colleges and Universities}

Colleges and universities to carry out teaching management information construction and do research and development of teaching management information system is a systematic project that needs for the close cooperation of several aspects. This paper divides the process of teaching management information construction into two stages of the development and implementation of information system platform.

\subsection{Research and Development Stage of Teaching Management Information System in Colleges and Universities}

The main task and objective of this phase is to carry out research and analysis, and theoretical research, form teaching management and its basic concepts, ideas and methods of information construction, and develop a teaching management information system for the training of school personnel and teaching management mode. For this purpose, this paper puts forward the "three sections" research and development process.

The first one is the research and development stage of taking the school as the main body. This stage is the basic work, divided into two main contents: the first is to carry out the theoretical study of the construction of teaching management system. Study the social needs and development trend of talent cultivation, College teaching management mode and modern information technology, and profound fusion method of the reform and development theory of modern higher education, explore the connotation and essence of modern teaching management, and form scientific teaching management and concept of information [5]. The second is to carry out the preparatory work of the construction of information system platform. Carry out research and investigation of the current situation of the construction and operation of the system of teaching management information, study the design of the system needs analysis, goal and module functions, development core concept and the main framework, and identify the key issues hindering the construction of teaching management information.

The second is the research and development stage that takes software development company as the main body. This stage is the realization of the information system platform. Software company, according to the top-level design requirements, further optimizes the structure of teaching management information system, analyzes the training mode of school personnel and teaching management mode, design the development process, and carry out development and realization of software programs. The third is the stage of continuous improvement and perfection. Schools, through a period of practice and application, analyze the scientific and operational feature of each module function, test if each module function is organically coupled, continuous improve the system functions.

\subsection{Implementation Stage of the Teaching Management Information System in Colleges and Universities}

After the teaching management information system is approved by the experts and authorized by the school, organize to carry out the implementation of information construction achievements. This paper puts forward "three sections" of the implementation process.

The first is propaganda and launch phase. Launch and promote in the whole school, all the 
school staffs and students comprehensively participate in, improve the awareness from the ideological aspect, and do well the implementation of mobilization and preparation work. The second is the implementation and application. Prepare for perfect results materials, rules compilation, and system user manual, do well the basic work of achievements implementation and application; establish implementation working group, responsible for technology, consulting, maintenance and guidance work of the implementation of project, and provide technical support and guarantee for the smooth implementation of the project results. The third is experience summary and continuous improvement. The project team is responsible for the summary and analysis of the results, and carry out continuous improvement by collaborating system development team to carry out the continuous improvement of the system function module and so on.

\section{Conclusion}

Under the background that the whole school running scale is very large, it is very important to promote the standard and level of teaching management through effective teaching management information construction. However, teaching management information construction is a complicated system project, and there are still some problems and deficiencies in the teaching management information construction of many Colleges and universities in our country. This study, first of all through the theoretical analysis, elaborates the theoretical foundation of the university teaching management information, and sorts out the concept and connotation of the university teaching management information. Then through the summary of the development process and current situation of the construction of teaching management information in Colleges and universities in China, and analyzes the three main problems existing in our current College teaching management information, namely the idea understanding deviation, lack of material conditions for guarantee, and insufficient extensive participation. And then learn from the experience of teaching management information system construction of foreign universities in developed countries, countermeasures to improve the construction of teaching management information in our Colleges and universities are proposed, namely strengthen the understanding of the great significance of teaching management information; improve the construction of information organization construction and highlight the top-level design; strengthen the publicity and promote the staffs participation; and perfect the relevant system for teaching management information.

\section{References}

[1] Hayden M, Thompson J. International schools and international education: Improving teaching, management and quality[M]. Routledge, 2013.

[2] Li Z, Shen H. Database Design on Teaching Management System Based on SQL Server[J]. 2016.

[3] Trout A T, Cohan R H, Ellis J H, et al. Teaching management of contrast reactions: does it work and how often do we need to refresh? [J]. Academic radiology, 2012, 19(4): 498-504.

[4] Chen D L, Chen L, Ji Q F. The Experimental Teaching Based on Hybrid Cloud Management System Research[C]//Applied Mechanics and Materials. Trans Tech Publications, 2013, 347: 2257-2260.

[5] Oral B. Student teachers' classroom management anxiety: A study on behavior Management and teaching management[J]. Journal of Applied Social Psychology, 2012, 42(12): 2901-2916. 